\title{
Magnetic Technique Estimation of Weld Residual Stress Failure Due to Tensile Loading
}

\author{
C. E. Etin-Osa ${ }^{*}{ }^{(\mathbb{B},}$, L. M. Ebhota ${ }^{2}$ \\ ${ }^{1}$ Department of Production Engineering, University of Benin, Benin, Nigeria \\ ${ }^{2}$ Groove Engineering \& Intergrated Services Limited, Port Harcourt, Nigeria \\ Email: ^etinosa.eruogun@uniben.edu,grooveengineeringservices@gmail.com
}

How to cite this paper: Etin-Osa, C.E. and Ebhota, L.M. (2021) Magnetic Technique Estimation of Weld Residual Stress Failure Due to Tensile Loading. Engineering, 13, 257-266.

https://doi.org/10.4236/eng.2021.136019

Received: April 11, 2021

Accepted: June 8, 2021

Published: June 11, 2021

Copyright $\odot 2021$ by author(s) and Scientific Research Publishing Inc. This work is licensed under the Creative Commons Attribution International License (CC BY 4.0).

http://creativecommons.org/licenses/by/4.0/

\begin{abstract}
In Nigeria, most welding activities are carried out by road side welders, majority of this welders are ignorant of weld residual stress and its adverse effect on weldment. Residual stress (RS) measuring device is vital in the measurement of inherent stresses in material. The aim of this research was to employ proof of principle in analyzing the weld residual stresses in a material. This was achieved by measuring samples with magnetic residual stress device and then subjecting the weld samples to mechanical tensile test with hope that materials with more residual stresses fail first. Finally the result from both procedures was compared to establish a relationship. Four (4) pieces of mild steel coupons measuring $100 \times 40 \times 3 \mathrm{~mm}$ were welded, producing two specimens, $A_{11}$ and $B_{11}$ of $200 \times 40 \times 3 \mathrm{~mm}$, respectively. The specimens were measured using the Magnetic device developed and 37 signals were obtained per specimen, thereafter, the welded specimens were subjected to tensile testing and results analyzed. From the results obtained, Specimen $A_{11}$ was observed to have the highest signal peak at the weld zone with RS signal of $20.3983 \mathrm{mV}$ compared to $B_{11}$ with $19.358 \mathrm{mV}$. While under tensile loading, it took $1.63 \mathrm{kN}$ to cause failure to specimen $A_{11}$ and $8.65 \mathrm{kN}$ for specimen $B_{11}$. From this simple experiment, it implies that the Magnetic RS device was able to mimic the behavior of residual stress and also predicted that $A_{11}$ would fail first.
\end{abstract}

\section{Keywords}

Residual Stress (R.S), Magnetic Barkhausen Noise (MBN), Signals, Tensile Test

\section{Introduction}

Welding can be regarded as the joining of two or more separate metals to form a 
single piece of metal with a permanent joint [1]. Residual stresses develop in welded materials due to sharp changes of temperature during welding [2]. Welding processes create heat at elevated temperatures which are transferred to the parent metal's matting interface for melting of the joints for bonding. If the heat is too high, it creates excessive heat input in the workpiece which results into a poorly welded joint as well as increase in residual stress, in and around the joint. On the other hand, low heat input also creates poor bonding of parent metal [3]. Therefore, the need to use a proper process parameter cannot be over emphasized. Usually, failures that result from these types of stresses are difficult to monitor by visual inspection, hence the need of a sophisticated device. Currently, there are no known welding process parameters that can totally eliminate residual stress in welded material [4] and [5]. In Nigeria, most welding activities are carried out by road side welders, and the majority of them are ignorant of weld residual stress and its adverse effect on welded joints. This type of stresses is known to encourage corrosion and reduce the load carrying capacity of weldment, it is very possible that some of the structural failures experienced in Nigeria, might result from this type of stresses [6] and [7].

The measuring of residual stress (R.S) can be done using three basic methods which are the "destructive", "semi-destructive" and "the non-destructive methods" [8]-[13]. For the Nigerian roadside welders, the non-destructive method is ideal and preferred in measuring/estimating stresses as materials would not need to be destroyed during measurement. The Magnetic Barkhausen Noise (MBN) residual stress measuring device is affordable and less complicated compared to the x-ray diffraction method. Although the x-ray diffraction method offers more accuracies and is more robust, but can only be applied in the lab as against the Magnetic Barkhausen Noise (MBN) which can be used outdoor. The Magnetic Barkhausen Noise (MBN) device can be locally fabricated using proof of principle.

The aim of this research was to measure residual stress signals in welded materials using magnetic residual stress device, employ proof of principle to analyze weld residual stress by subjecting weld samples to mechanical tensile test, with hope that materials with more residual stresses fail first and also compare both results obtained to establish the efficiency of the device.

\section{Materials and Methods}

\subsection{Materials}

$6 \mathrm{~mm}$ Mild steel plate was purchased locally, the material was cut into four (4) pieces coupons measuring $100 \times 40 \times 3 \mathrm{~mm}$, and welded. The process parameters in Table 1 were emplyed in the welding process, using the stick arc welding machine having a constant voltage of 62 volts and an adjustable current. The reason for varying the current was to introduce different magnitude of residual stresses to the weldment. The four (4) pieces were welded to form two specimen, $A_{11}$ and $B_{11}$ of $200 \times 40 \times 3 \mathrm{~mm}$ respectively. This specimen was measured using 
Table 1. Weld process parameters.

\begin{tabular}{cccc}
\hline Sample & Current (Amp) & Voltage $(\mathrm{V})$ & Weld Speed $(\mathrm{mm} / \mathrm{s})$ \\
\hline $\mathrm{A}_{11}$ & 130 & 62 & 2.063 \\
$\mathrm{~B}_{11}$ & 120 & 62 & 2.497 \\
\hline
\end{tabular}

the magnetic device developed locally by [14], the unit readings obtained from this measuring device are in milli-volts. During measurment, minute voltages which result from magnetic domain flip in the mild steel material, are detected by the pickup coil as the device moved over the surface of the specimen. The pulsating voltages are continously fed to the inbult amplifier in the device for magnification, presented in Figure 1 is the setup of the device for measurement. The graphical user interphase (GUI) was developed using LabVIEW as shown in Figure 2. The Residual stress measuring device was designed using arduino nano, and enhanced to 16 bits resolution using ADS1115 which was connected directly to the pickup coil in Figure 3. The welded specimens were tack welded as seen in Figure 4 before actual welding and chamfering to the dogbone shaped shown in Figure 5. The tensile testing machine used for the mechanical test is presented in Figure 6.

\subsection{Method}

Specimen $A_{11}$ and $B_{11}$ were measured using the magnetic residual stress (R.S) measuring device [14]. Five repeated readings were collected and compared for consistency, with combined time series plot for $A_{11}$ and $B_{11}$ presented in Figure 7 and Figure 8. Thirty-seven signals were generated per reading from the welded metal in milliVolts. Thereafter, the two specimens were subjected to tensile test with the hope that the specimen with more residual stress would fail first under tensile loading. The weld RS was measured along the longitudinal directions of the plate as shown in Figure 9. Measurements using the magnetic device were carried out on the specimens, before the materials were subjected to mechanical test.

\section{Results and Discussion}

\subsection{Results}

Table 2 shows the magnetic R.S signals generated in millivolts from the welded specimen $A_{11}$ and $B_{11}$ using the device.

The 1st, 2nd, 3rd, 4th and 5th reading presented in Figure 7 and Figure 8 for $A_{11}$ and $B_{11}$ shows a good agreement. First (1st) magnetic readings from $A_{11}$ and $B_{11}$ were selected to form Table 2. The $A_{11}$ and $B_{11}$ from Table 2, were then employed to plot the time series graph shown in Figure 10. From this graph, it was observed that Specimen $A_{11}$ had the highest peak signal at the weld zone with magnetic R.S signal of $20.3983 \mathrm{mV}$ compared to $B_{11}$ with $19.358 \mathrm{mV}$. After the readings where obtained, the two specimen were subjected to tensile test. After the readings were obtained from the specimen, the two specimen were subjected to tensile test, with results presented in Table 3. 


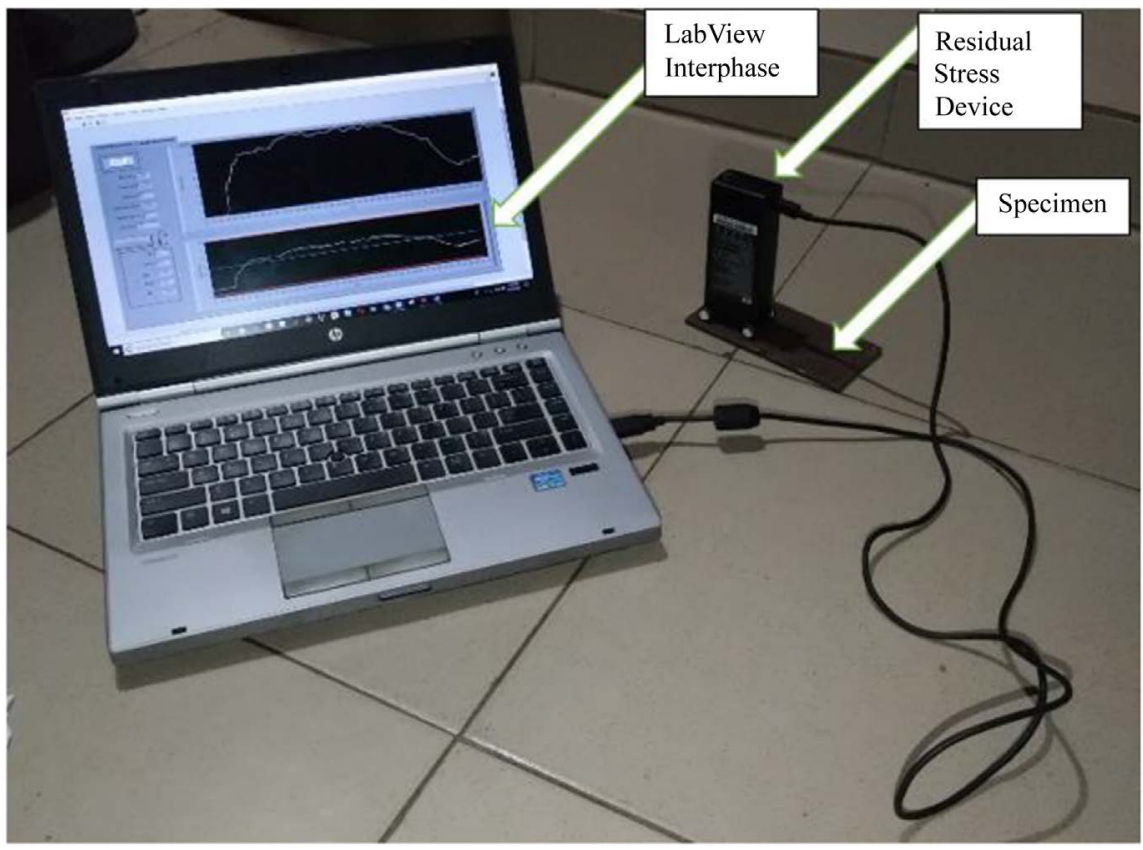

Figure 1. Magnetic measuring device.

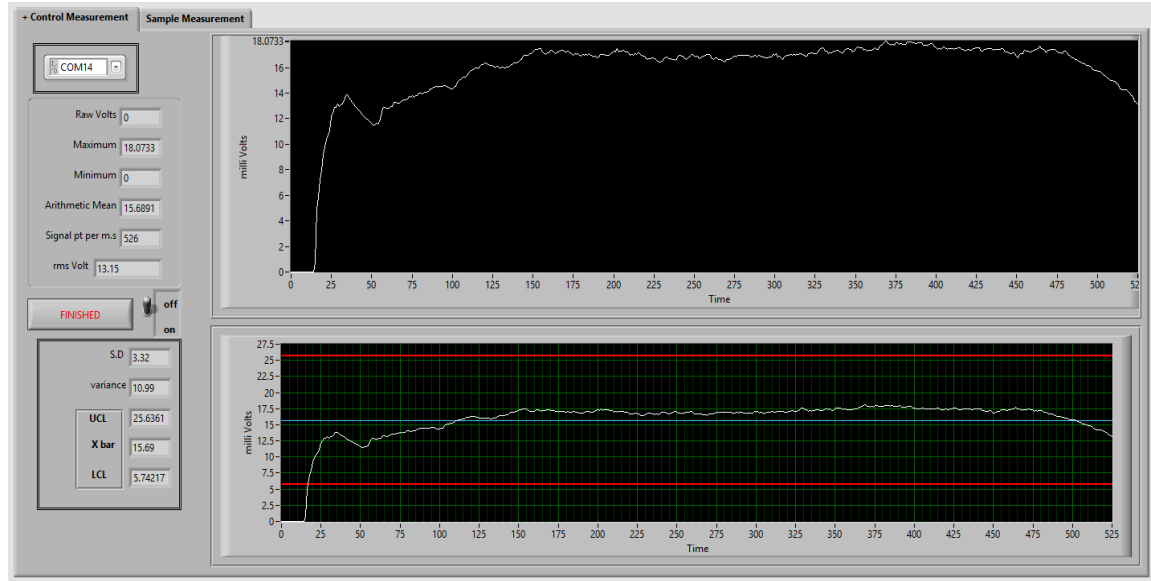

Figure 2. GUI for the local MBN device.

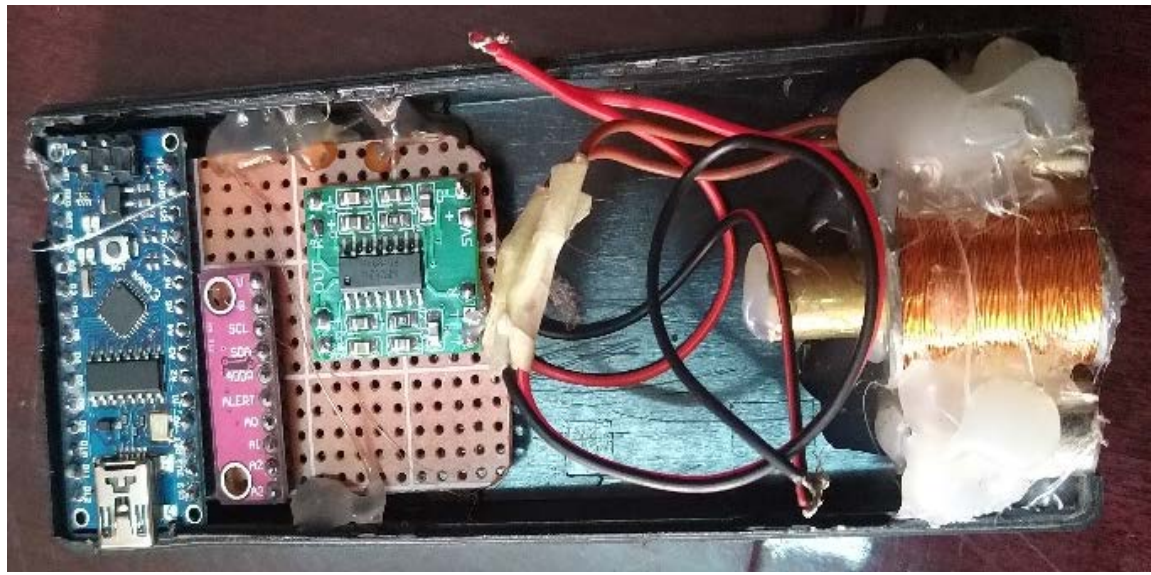

Figure 3. Internal component of magnetic device. 


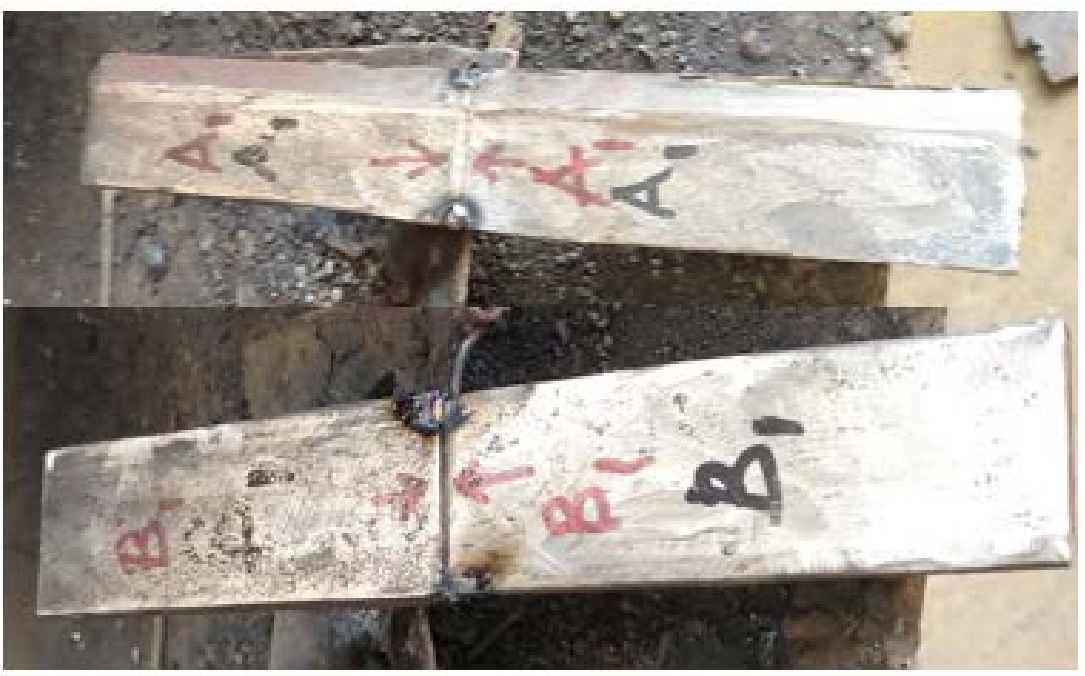

Figure 4. $A_{11}$ and $B_{11}$ tack welded specimen.

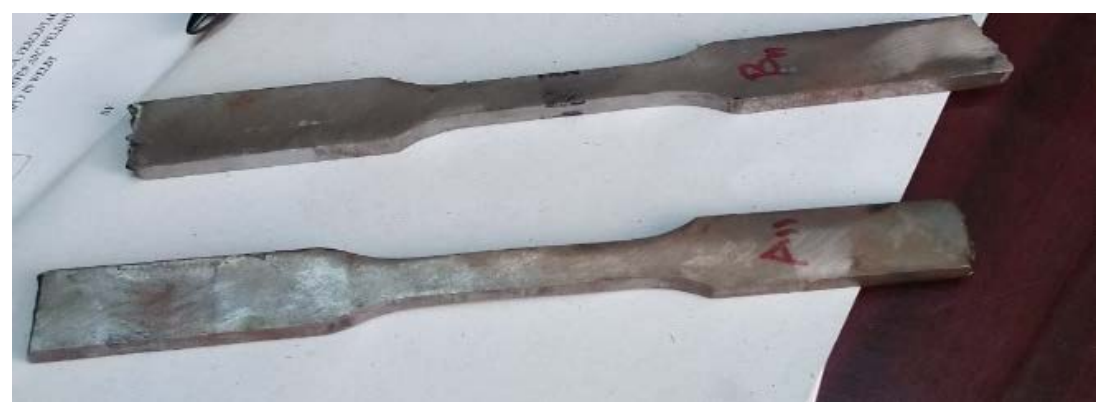

Figure 5. Dogbone specimen for $A_{11}$ and $B_{11}$.

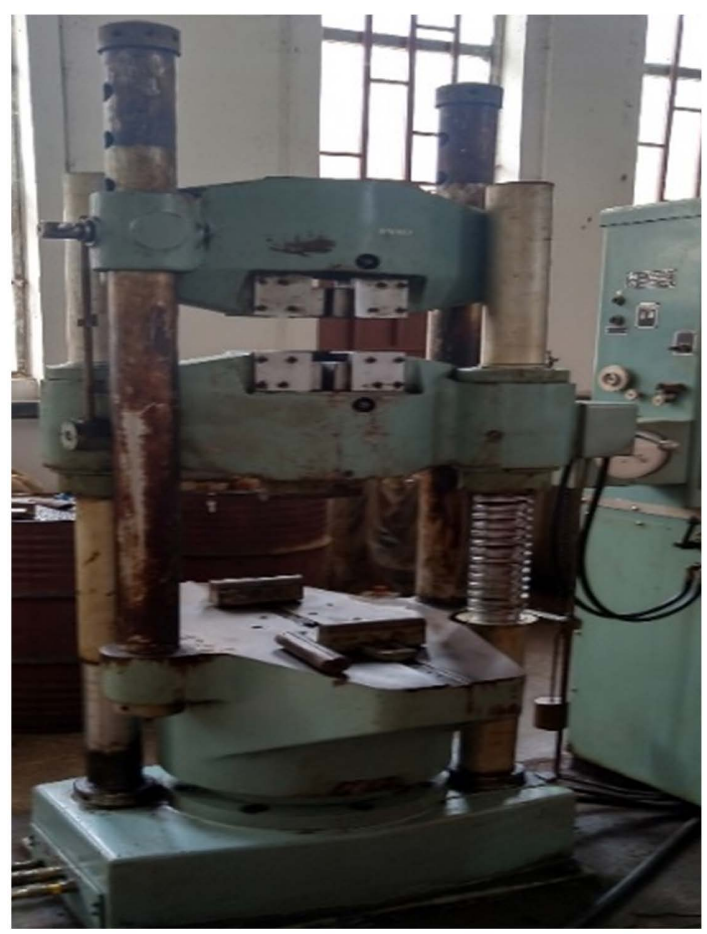

Figure 6. Tensile testing machine. 


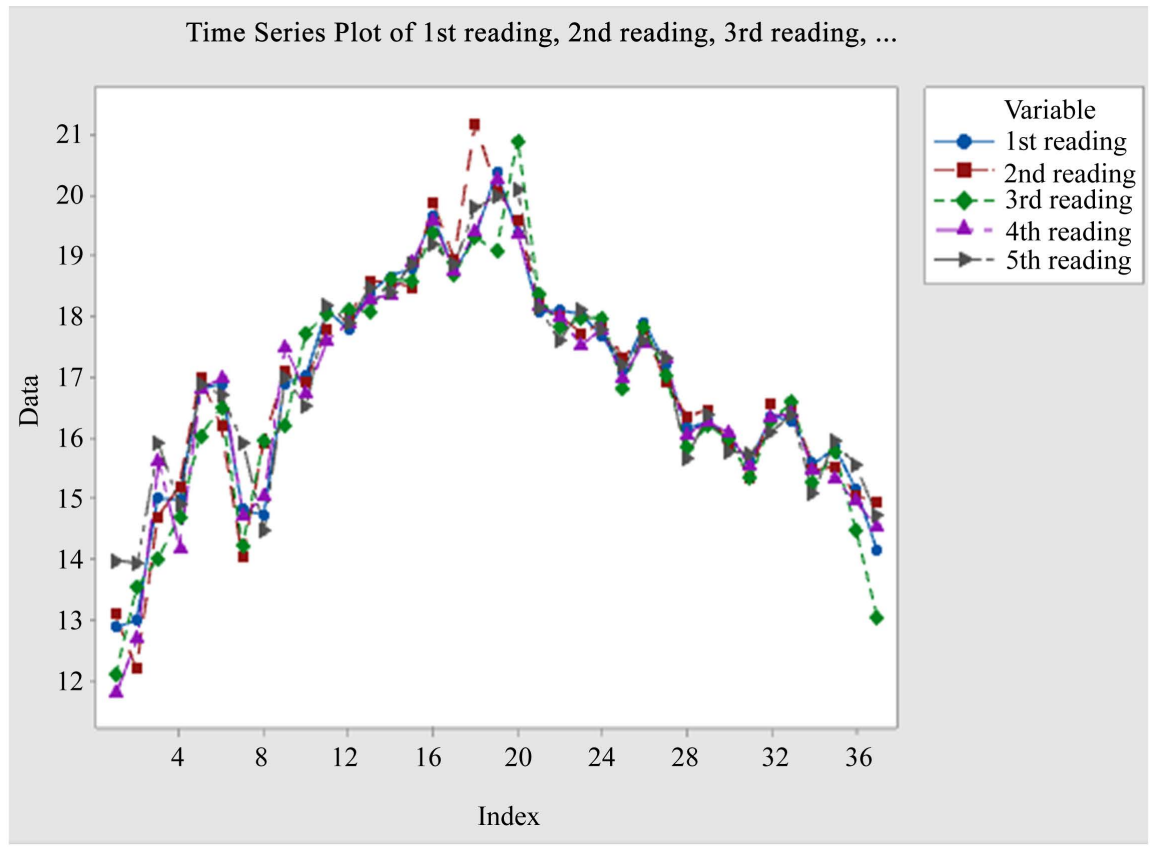

Figure 7. Combined time plot for 1st, 2nd, 3rd, 4th and 5th signal for $\mathrm{A}_{11}$.

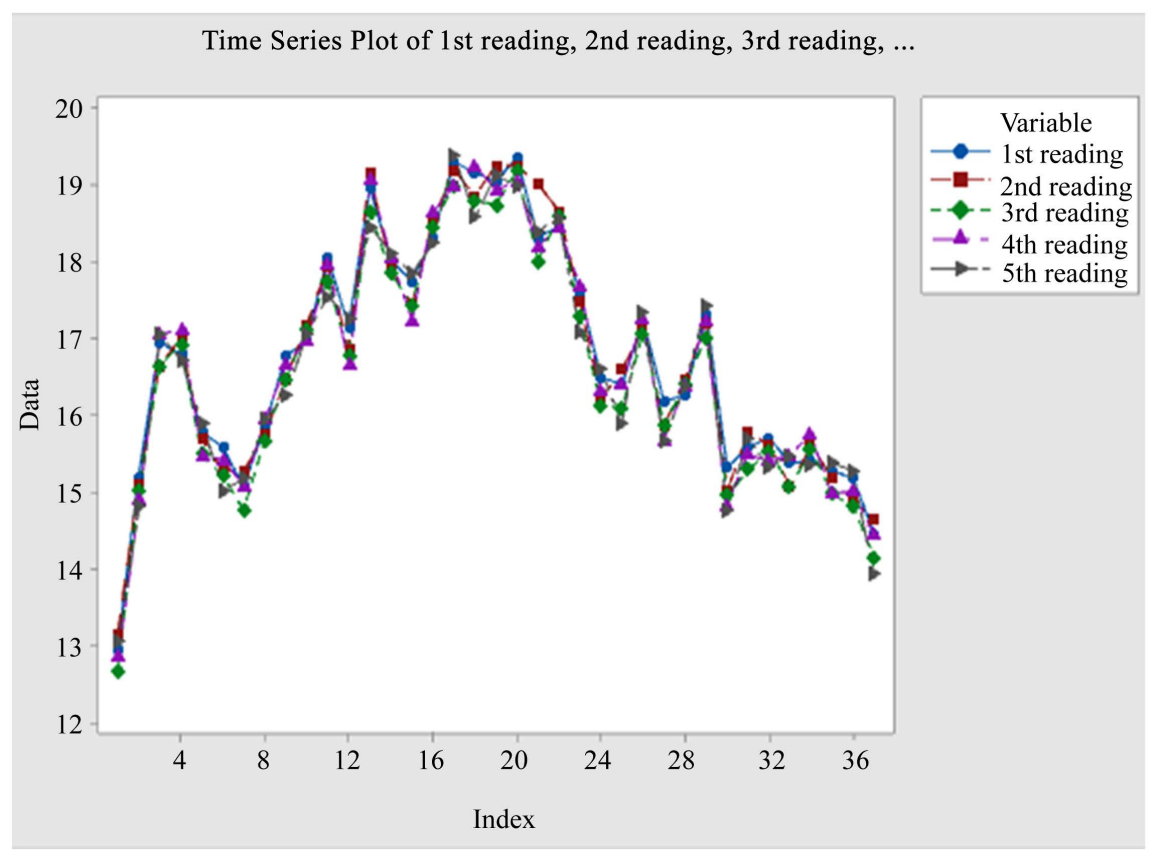

Figure 8. Combined time plot for 1st, 2nd, 3rd, 4th and 5th signal for $\mathrm{B}_{11}$.

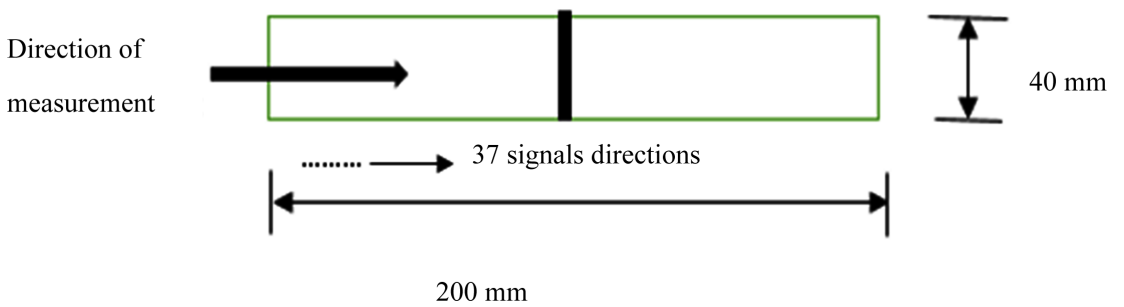

Figure 9. Direction of R.S Measurement on specimen. 


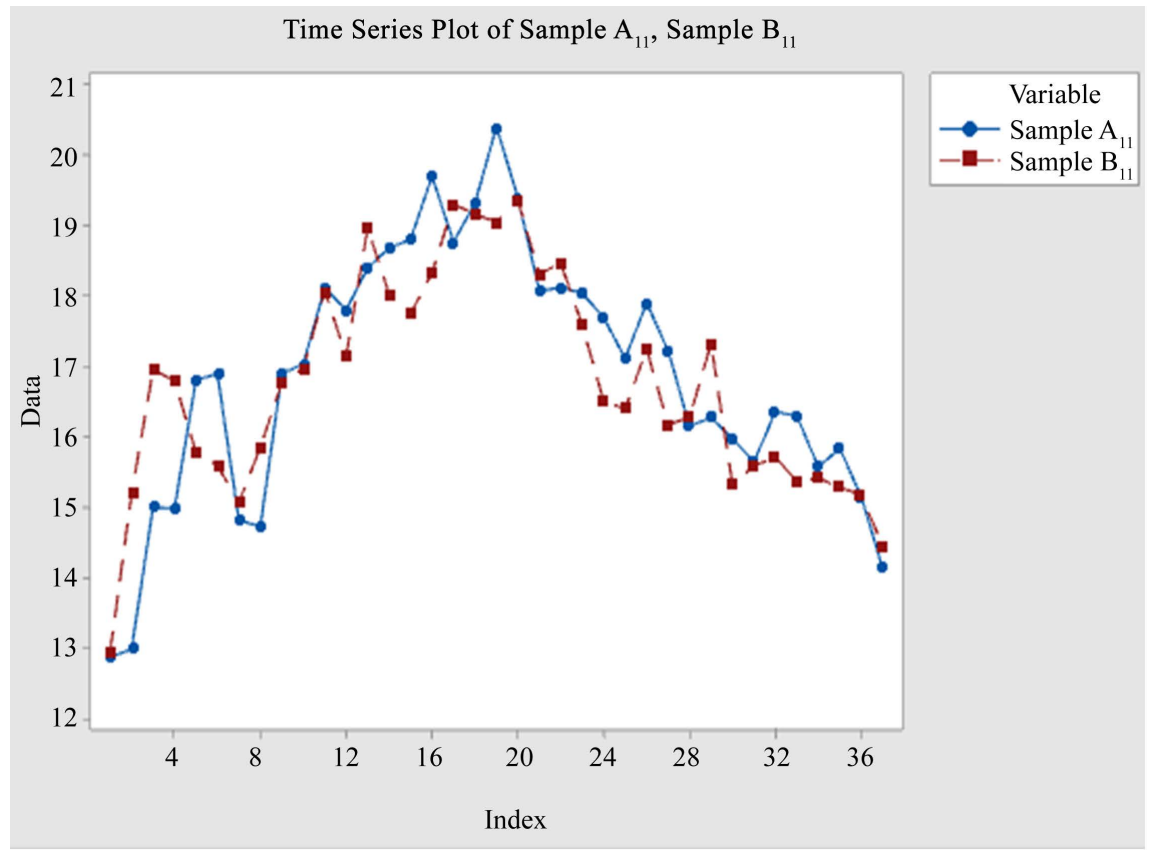

Figure 10. Combined time series plot for sample $A_{11}$ and Sample $B_{11}$ (Experimental).

Table 2. Magnetic RS signal Results from specimen $A_{11}$ and $B_{11}$.

\begin{tabular}{|c|c|c|c|c|c|c|c|c|}
\hline \multirow[b]{2}{*}{$\mathrm{S} / \mathrm{N}$} & \multicolumn{2}{|c|}{ Experiment } & \multirow[b]{2}{*}{$\mathrm{S} / \mathrm{N}$} & \multicolumn{2}{|c|}{ Experiment } & \multirow[b]{2}{*}{$\mathrm{S} / \mathrm{N}$} & \multicolumn{2}{|c|}{ Experiment } \\
\hline & $\begin{array}{c}\text { Sample } \\
\mathrm{A}_{11}(\mathrm{mV})\end{array}$ & $\begin{array}{c}\text { Sample } \\
\mathrm{B}_{11}(\mathrm{mV})\end{array}$ & & $\begin{array}{c}\text { Sample } \\
\mathrm{A}_{11}(\mathrm{mV})\end{array}$ & $\begin{array}{c}\text { Sample } \\
\mathrm{B}_{11}(\mathrm{mV})\end{array}$ & & $\begin{array}{c}\text { Sample } \\
\mathrm{A}_{11}(\mathrm{mV})\end{array}$ & $\begin{array}{c}\text { Sample } \\
\mathrm{B}_{11}(\mathrm{mV})\end{array}$ \\
\hline 1 & 12.8809 & 12.95 & 14 & 18.6835 & 18.0254 & 27 & 17.2299 & 16.177 \\
\hline 2 & 12.9952 & 15.1971 & 15 & 18.8031 & 17.7502 & 28 & 16.1576 & 16.2796 \\
\hline 3 & 15.0061 & 16.9532 & 16 & 19.6994 & 18.3294 & 29 & 16.2763 & 17.3237 \\
\hline 4 & 14.9904 & 16.7997 & 17 & 18.7687 & 19.3058 & 30 & 15.9829 & 15.3248 \\
\hline 5 & 16.8099 & 15.7911 & 18 & 19.3166 & 19.1585 & 31 & 15.6465 & 15.5936 \\
\hline 6 & 16.9002 & 15.5948 & 19 & 20.3983 & 19.0515 & 32 & 16.3629 & 15.7148 \\
\hline 7 & 14.8209 & 15.0768 & 20 & 19.3983 & 19.358 & 33 & 16.2984 & 15.3768 \\
\hline 8 & 14.7334 & 15.8554 & 21 & 18.0721 & 18.3155 & 34 & 15.5793 & 15.4212 \\
\hline 9 & 16.901 & 16.7733 & 22 & 18.1208 & 18.4627 & 35 & 15.8385 & 15.2856 \\
\hline 10 & 17.0368 & 16.9787 & 23 & 18.0433 & 17.5904 & 36 & 15.1553 & 15.1853 \\
\hline 11 & 18.1157 & 18.0628 & 24 & 17.6922 & 16.5015 & 37 & 14.1407 & 14.4525 \\
\hline 12 & 17.8038 & 17.1557 & 25 & 17.117 & 16.4052 & & & \\
\hline 13 & 18.3986 & 18.9685 & 26 & 17.9042 & 17.2461 & & & \\
\hline
\end{tabular}

Table 3. Tensile test for $A_{11}$ and $B_{11}$.

\begin{tabular}{ccc}
\hline $\mathrm{S} / \mathrm{N}$ & Specimen & Tensile Test \\
\hline 1 & $\mathrm{~A}_{11}$ & $1.63 \mathrm{kN}$ \\
2 & $\mathrm{~B}_{11}$ & $8.65 \mathrm{kN}$ \\
\hline
\end{tabular}




\section{Tensile Stress Test}

Is a great way to examine the strength of a material by pulling on it. During the pulling of the specimen by the machine, the machine scale would indicate how much force it is applying to pull the specimen apart. When tensile test is performed, it is used to measure how much stress is built-up in the material. Specimen $A_{11}$ and $B_{11}$ already have some accumulated residual stresses as result of the weld activity on the material, therefore it is expected that the material with more accumulated R.S would fail first under tensile loading. Table 3 present the results of the tensile test experiment.

From the result presented in Table 3, it was observed that it took a minimum load of $1.63 \mathrm{kN}$ to cause failure to specimen $A_{11}$ under tensile loading while specimen $B_{11}$ withstood up to $8.65 \mathrm{kN}$ before failure which also concur to the Magnetic device estimated readings obtained for sample $A_{11}$ and $B_{11}$.

\subsection{Discussion}

Ferromagnetic materials can exhibit attraction when a magnet is brought close to or away from them, which creates a magnetic attractive effect on them. This magnetic effect is generated due to the magnetic domains flipping into positions inside the ferromagnetic material, creating an imbalance on the net magnetic effect inside the material, making the ferromagnetic material behave like a magnet, this imbalance usually cancels out when a lightly tap or shake is delivered to the material. The principle, discovered by bark hausen has been applied to measure residual stresses in ferromagnetic material as it is known that magnetic domain usually experience obstacles while flipping into position due to presence of impurities or inherent stresses in the material [15]. The Magnetic Barkhausen principle was applied in this work using a locally made magnetic device to estimate the magnitude of stresses present in the material. The results were then compared to the tensile test experiment performed on both specimen. It was observed from Figure 7 in the comparison of all $A_{11}$ results that good agreement existed between the 1st, 2nd, 3rd, 4th and 5th readings. Good agreement was also established for $B_{11}$ in Figure 8, the repeated experiment was applied to certify the reliability of the device in reproducing experiments of approximate results. The first responses from $A_{11}$ and $B_{11}$ presented in Table 2 were chosen after Figure 7 and Figure 8 produced a strong correlation between repeated readings respectively. The results in Table 2 were applied to create the time series plot presented in Figure 10, $A_{11}$ was then observed to have higher signal of 20.3983 $\mathrm{mV}$, as compared to $B_{11}$ with $19.358 \mathrm{mV}$, and according to [16], material that has higher residual stresses tends to fail first under a given load. From the tensile test carried out on both $A_{11}$ and $B_{11}, A_{11}$ failed under a lesser load of $1.63 \mathrm{kN}$, while $\mathrm{B}_{11}$ withstood a better load of up to $8.65 \mathrm{kN}$ as predicted by the device.

\section{Conclusion}

In this research, specimen $A_{11}$ and $B_{11}$ welded with welding current of $130 \mathrm{Amp}$ and $120 \mathrm{Amp}$ at $62 \mathrm{~V}$ each were measured using the locally made magnetic resi- 
dual stress estimating device. It was observed that the device was able to estimate residual stress signals in weldment and showed that $A_{11}$ had more residual stress, but nosedived in clearly giving a good marginal difference between the two specimens, this shortfall in accuracy was somehow tied to the pickup coil design and its limitation. Hence, a second opinion, like the mechanical test would always be required for accurate conclusion. This technique can be improved upon to suit the Nigeria welding industries and help with better decision making during and after welding, to predict durability of welded components. The Nigerian fabrication industry especially the roadside artisans in time past, welded metals without knowing the nature or magnitude of RS present before or after weld which is regarded as "blind welding", such types of welding have resulted in numerous failure of components at different magnitudes and also aided quick corrosion activities in welded metals. $\mathrm{A}_{11}$ was observed to have higher signal of $20.3983 \mathrm{mV}$ and failed under a minimum load of $1.63 \mathrm{kN}$ while $B_{11}$ with 19.358 $\mathrm{mV}$ had a lesser residual stress, hence was able to withstand stresses up to 8.65 $\mathrm{kN}$.

\section{Conflicts of Interest}

The authors declare no conflicts of interest regarding the publication of this paper.

\section{References}

[1] Etin-osa, C.E. and Achebo, J.I. (2017) Analysis of Optimum Butt Welded Joint for Mild Steel Components Using FEM (ANSYS). American Journal of Naval Architecture and Marine Engineering, 2, 61-70. https://doi.org/10.11648/j.aas.20170206.12

[2] James, M.N. (2010) Residual Stress Influences in Mechanical Engineering. XVIII Congreso Nacional de Ingeniería Mecánica, 1-13.

[3] Jeffus, L. (2012) Chapter 1: Introduction to Welding. In: Welding Principle and Application, Delmar Cengage Learning, New York, 4-23.

[4] Anowa, H.D., Achebo, J.I., Ozigagun, A. and Etin-osa, E.C. (2018) Analysis of Weld Molten Metal Kinematic Viscosity of Tig Mild Steel Weld. International Journal of Advanced Engineering and Management Research, 3, 14-30.

[5] Imhansoloeva, N.A., Achebo, J.I., Obahiagbon, K.O., Osarenmwinda, J.O. and Etin-Osa, C.E. (2018) Optimization of the Deposition Rate of Tungsten Inert Gas Mild Steel Using Response Surface Methodology. Engineering, 10, 784-804. http://www.scirp.org/journal/eng https://doi.org/10.4236/eng.2018.1011055

[6] The Sensor (2019). https://www.sensornewsonline.com.ng/history-building-collapse-nigeria

[7] Vanguard (2018). https://www.vanguardngr.com/2018/12/building-collapse-31-persons-rescued-15-d ead-says-nema

[8] Withers, P.J., Turski, M., Edwards, L., Bouchard, P.J. and Buttle, D.J. (2008) Recent Advances in Residual Stress Measurement. International Journal of Pressure Vessels and Piping, 85, 118-127. https://doi.org/10.1016/j.ijpvp.2007.10.007 
[9] Donato, G.H.B. and Magnabosco, R. (2014) Modeling and Characterization of Residual Stresses in Material Processing. Comprehensive Materials Processing. Materials Modeling and Characterization, 2, 219-233.

https://doi.org/10.1016/B978-0-08-096532-1.00218-1

[10] Withers, P.J. and Bhadeshia, H.K.D.H. (2001) X Residual Stress: Part 1 Measurement Techniques. Materials Science and Technology, 17, 355-365.

https://doi.org/10.1179/026708301101509980

[11] Withers, P.J. and Bhadeshia, H.K.D.H. (2001) Residual Stress: Part 2 Nature and Origins. Materials Science and Technology, 17, 366-375. https://doi.org/10.1179/026708301101510087

[12] Rossini, N.S., Dassisti, M., Benyounis, K.Y. and Olabi, A.G. (2012) Methods of Measuring Residual Stresses in Components. Materials and Design, 35, 572-588. https://doi.org/10.1016/j.matdes.2011.08.022

[13] Niku-Lari, A. (1983) Residual Stresses and Surface Finish in Shot-Peened Components and Materials. Experimental Techniques, 7, 31-37. https://doi.org/10.1111/j.1747-1567.1983.tb01711.x

[14] Etin-Osa, C.E., Achebo, J.I. and Obahiagbon, K.O. (2020) Design and Fabrication of Portable Weld Residual Stress Measuring Device Using MBN Principle. NIPES Journal of Science and Technology Research, 2, 70-84. https://doi.org/10.37933/nipes/2.3.2020.8

[15] Titto, K. (1987) Use of Barkhausen Effect in Testing for Residual Stresses and Material Defects. Proceedings of ASM s Conference on Residual Stress in Design, Process, and Materials Selection, Cincinnati, 27-29 April 1987, 27-35.

[16] Etin-Osa, D. and Etin-Osa, C.E. (2019) Forensic Science and the Nigerian Society. Journal of Nuclear Sciences, 6, 17-21. http://jns.ankara.edu.tr 